\title{
THE ROLE OF INDUSTRIES IN THE NEW PRODUCT DEVELOPMENT POINT: A RESEARCH IN KAHRAMANMARAS METAL KITCHEN INDUSTRY
}

\author{
DOI: 10.17261/Pressacademia.2018.927 \\ PAP- V.7-2018(80)-p.418-421
}

Nusret Goksu ${ }^{1}$, Alaeddin Koska², Mehri Banu Erdem ${ }^{3}$, Ayse Yilmaz ${ }^{4}$

${ }^{1}$ Kahramanmaraş Sütçü İmam Üniversitesi, Kahramanmaraş, Türkiye. nusretgoksu@gmail.com

${ }^{2}$ Kahramanmaraş Sütçü İmam Üniversitesi, Kahramanmaraș, Türkiye. addinkoska@gmail.com

${ }^{3}$ Kahramanmaraş Sütçü İmam Üniversitesi, Kahramanmaraş, Türkiye. mehri-banu@hotmail.com

${ }^{4}$ Kahramanmaraş Sütçü İmam Üniversitesi, Kahramanmaraş, Türkiye. ayse_ylmz@ @otmail.com, ORCID: 0000-0002-0606-1117

To cite this document

Goksu, N., Koska, A., Erdem, M. B., Yilmaz, A. (2018). The role of industries in the new product development point: a research in Kahramanmaras metal kitchen industry. PressAcademia Procedia (PAP), V.7, p.418-421.

Permemant link to this document: $\mathrm{http}: / /$ doi.org/10.17261/Pressacademia.2018.927

Copyright: Published by PressAcademia and limited licenced re-use rights only.

\section{ABSTRACT}

Today, when market conditions and technology are constantly changing and differentiating, businesses are looking for ways to achieve sustainable competitive advantage. The key to sustainable competitive advantage is to follow innovations. One of the innovations is the industry 4.0 concept that we have heard often lately. Industry 4.0 ensures that the end-user consumer needs are met faster, more flexibly and productively at every stage of production. Enterprises are aware that processes are long and risk-filled to create new products. Managing the process in the right way is the process of following innovations. One of the sectors that will be most affected by changes is undoubtedly the metal kitchen industry.

Purpose- It examines Industry 4.0 approaches of firms in metal kitchen industry operating in Kahramanmaraş province.

Conclusion- Information about Industry 4.0 is provided.

Keywords: New product development, technology, metal kitchen industry, industry 4.0.

JEL Codes: 014, 01, 010

\section{YENI ÜRÜN GELIŞTIRME NOKTASINDA ENDÜSTRI 4.0 ROLÜ: KAHRAMANMARAŞ METAL MUTFAK} SANAYIINDE BIR ARAŞTIRMA

\section{ÖZET}

Piyasa şartlarının ve teknolojinin sürekli değişip, farklılaştığı günümüzde işletmeler sürdürülebilir rekabet avantajı elde etmenin yollarını aramaya başlamışlardır. Sürdürülebilir rekabet avantajının anahtarı ise yenilikleri takip etmekten geçmektedir. Bu yeniliklerden birisi de son zamanlarda sıkça duyduğumuz endüstri 4.0 kavramıdır. Endüstri 4.0, üretimin her aşamasında dijitalleşme sonucu tüketici gereksinimlerini daha hızlı, esnek ve verimli bir biçimde karşılanmasını sağlamıştır. İşletmeler yeni ürün oluşturmak için uzun ve risklerle dolu bir süreç olduğunun farkındadırlar. Bu sürecin doğru bir şekilde yönetilmesi ise yenilikleri takip etmekten geçmektedir. Üretim sistemlerindeki bu değişimlerden en çok etkilenecek sektörlerden birisi de şüphesiz metal mutfak sanayisidir.

Amaç- Kahramanmaraş ilinde faaliyet gösteren metal mutfak sanayiindeki firmaların Endüstri 4.0 yaklaşımlarını incelemektir.

Sonuç- Endüstri 4.0 hakkında bilgi verilmiştir.

Anahtar Kelimeler: Yeni ürün geliştirme, teknoloji, metal mutfak sanayii, endüstri 4.0.

JEL Kodları: 014, 01, 010 


\section{GíRiş}

Son yıllarda piyasa ve teknolojideki değişimler kayda değer ölçüde artmıştır. İşletmelerin yeni ürün geliştirmeleri konusunda gösterdikleri özen değişen pazarda rekabetçi güç olarak izlenilmesi gereken önemli bir yoldur. Yeni ürün geliştirmek uzun vadeli ve risklerle dolu bir süreçtir bu yüzdendir ki işletmeler bu süreci doğru yönetebilmek adına yeniliklerden uzak kalmalıdır. Bu yeniliklerden birisi de son zamanlarda sıkça duyduğumuz endüstri 4.0 kavramıdır. 4. Endüstri Devrimi”, "Akılı üretim” veya "Endüstriyel internet" olarak adlandırılan bu yenilik, dijital ve fiziksel süreçlerin entegrasyonu ile akıllı ürünlerin akıllı fabrikalarda üretilmesini ve dağıtılmasını sağlayan teknolojiler kümesi olarak tanımlanır(Şekkeli ve Bakan,2018:18).Üretim sistemlerindeki bu değişimlerden en çok etkilenecek sektörlerden biri de metal mutfak sanayisidir. Bu çalışmada Yeni ürün geliştirme kavramı Endüstri 4.0’ın ne olduğu, neler içerdiği ve olası etkileri hakkında teorik bilgiler sunulmuştur.

\section{LITERATURE INCELEMESI}

\section{Yeni Ürün Geliştirme}

Ekonomideki küreselleşme, ileri teknoloji, sıklıkla değişen müşteri ihtiyaçları, ürün ömrünü kısaltmakta ve artan yıkıcı rekabet dolayısıyla iş dünyasına yeni zorluklar getirmektedir(Srinivasan ve Brush,2006:436). Yeni ürün geliştirme; İşletmelerin yeni ürün oluşturmak amacıyla giriştiği uzun ve risklerle dolu bir süreçtir. Bu süreç, hem işletmelerin kontrol edemediği dış çevresel faktörler hem de firma içi faktörlerden etkilenir(Sanders ve Monrodt,1994:98) İşletmeler yeni ürün geliştirme sürecinin farklı evrelerinde verecekleri doğru kararlar sayesinde yeni ürünün başarısı karşısındaki belirsizlikleri azaltarak riski minimum düzeye indirebilirler. İşletmelerin doğru kararlar verebilmeleri onların yeni ürün geliştirme başarısını etkileyen faktörleri göz önünde bulundurmaları ile alakalı bir durumdur(Cengiz vd.,2005:134). Yeni ürün geliştirme süreci sistematik bir biçimde uygulanmalıdır. Aynı zamanda bu süreç yeniliğin türü, geliştirilen ürünün özellikleri, işletmenin niteliğine göre farklı aşamalardan oluşabilmektedir.(Ecer ve Canıtez,2004:193).Aynı zamanda işletmeler son dönemdeki gelişmeleri takip ederek ürün üretimleri yapılmasına dikkat etmelidir. Son dönemlerde gündemde olan yeni bir kavram olan Endüstri 4.0 yardımı ile işletmeler yeni ürün oluşturma aşamalarında daha esnek, hızlı ve minimum hatalı ürünler üretilmesini sağlayacaklardır. Kahramanmaraş ilini düşündüğümüzde ise metal mutfak sanayinde faaliyet gösteren çok sayıda firma bulunmaktadır. Ayrıca sektör olarak rekabet oldukça şiddetlidir. Bu yüzden de metal mutfak sanayi fabrikalarının da en kısa zamanda bu yeni dönüşüme ayak uydurmaları gerektiği açıktır. Endüstri 4.0 kısaca, tüketcinin değişen ihtiyacına anlık olarak uyum sağlayan üretim sistemlerinden oluşan ve aynı zamanda birbirleriyle sürekli iletişim ve koordinasyon halinde olan otomasyon sistemleridir denilebilir.

Endüstri Devirlerinin Gelişimi: Günümüze kadar yaşanan bütün endüstriyel devrimlerin ülke ve toplum gelişiminde çok önemli etkileri olduğu görülmektedir. Devrimlerin her biri, ekonomi, sosyal, bilimsel ve kültürel birçok değişimler üzerinde bir rol oynamıştır(Ovacı,2017:115). Her bir devrim ile yapılan inovasyonlar sonucunda çok sayıda toplumsal değişimi etkilemiştir. Buhar makinesinin icat edilmesiyle birlikte tetiklenen endüstri devrimi toprağa, tarıma ve insan gücüne dayalı atölye tipi üretimden makinelere ve seri üretimle şekillenen yeni ve farkı bir üretim tipine geçiş sağlanmıştır. Bu dönem 1.sanayi devrimi olarak adlandırılmış ve ilk kez İngiltere'de başlayıp dünya ülkelerine yayılmıştır(Ersoy,2016:5). İkinci Endüstri Devrine gelindiğinde ise, bu dönem teknoloji devrimi olarak da adlandırılır. İkinci Endüstri Devrimi’nin temellerinin atılmasındaki önemli nedenlerden birisi de demiryollarının gelişmesiyle hammaddelerin temin edilmesi kolaylaşmış aynı zamanda uzak pazarlara kolaylıkla ulaşımın gerçekleşmiş olmasıdır(Janicke ve Jacob, 2009;Akt; Pamuk,2017:2). Bu dönemde; buhar kömür ve demirin yanında üretim sürecinde çelik, elektrik, petrol ve kimyasal maddeler de kullanılmaya başlanmıştır. Böylece endüstri daha da gelişmiştir(Ersoy,2016:6). Ayrıca bu dönemde, Henry Ford hareketli akış bantlarını fabrikalarında kullanmaya başlamış ve seri üretime geçişte önemli bir rol oynamıştır (Alizon vd., 2009).Bu gelişmeler neticesinde, telefon, daktilo, gazete vb. haberleşme araçlarının gelişmesiyle haberleşme hızlanmış böylelikle insanlar arasındaki uzaklık azalmıştır. Kentleşme hızla büyümeye başlamış aynı zamanda insanların yaşam standartları yükselmeye başlamıştır. Birinci Endüstri Devrimi, İngiltere ve Avrupa'da etkisini gösterirken İkinci Endüstri Devrimi ise, ABD, Japonya gibi ülkelerde de yaygınlaşmıştır(Pamuk,2017:3).Üçüncü Endüstri Devrimi ise, üretimin otomasyonlu hale gelmesi ve sayısallaşmasıdır. Ayrıca bu dönemde, bilgisayar, fiber optik, lazer gibi teknolojilerin gelişimi üretimin yönünün ve biçimini etkilemiştir. Bunlara ek olarak dünya kaynaklarının hızla tükeniyor hale gelmesinden dolayı sürdürülebilirlik kavramının gündeme gelmesine neden olmuştur(Ersoy,2016). Sanayi devrimindeki değişimler bilgi toplumunun oluşmasına neden olmuştur. Bilgi toplumunun geldiği son ve yeni sanayi devrimi ise Endüstri 4.0 ortaya çıkmıştır(Çeliktaş vd,2015:1). Endüstri 4.0 veya Dördüncü Sanayi Devriminin amacı dijitalleşmenin getirdiği olanak ve inovasyon ile birlikte üretimde daha verimli ve aynı zamanda daha rekabetçi hale gelmesi amaçlanmaktadır (Dengiz,2017:39). Endüstri 4.0, makinelerin ve ürünlerin, herhangi bir insan müdahalesi olmaksızın birbiriyle iletişim kurabildiği üretim ağıdır. Endüstri 4.0 geleneksel boyuttaki endüstri üretiminin ileri bir teknoloji ile donatılarak bilişim çağının üretim süreçlerinde yepyeni bir boyut kazandırdığı yeni süreç olarak tanımlanabilir. Kısaca; bir yandan tüketicinin değişen ihtiyaçlarına anlık bir şekilde uyum sağlayan üretim sistemlerini, öteki taraftan ise birbiriyle sürekli iletişim ve koordinasyon halinde olan sistemler olarak tanımlanır.

Endüstri 4.0 İlk defa 2011 yılında Hannover Fuarında ortaya çıkan Endüstri 4.0 yeni bir sanayi devriminin habercisi olmuştur (MacDougall, 2011).Üretimde yeni bir dönemin başladığı ve bilişim çağının daha modern bir hal alarak üretim teknolojilerinin en üst seviyeye taşınmakta olduğu bu fuarda anlatılmıştır. Alman Hükümeti tarafından konu ile ilgili çalışmaları sürdürecek bir grup oluşturmuştur(Ebso,2015:7). Endüstri 4.0'ın ortaya çıkmasının nedenlerine bakacak olursak; Tüketicinin değişen ve çeşitlenen talepleri ilk nedendir. Artık tüketiciler, küreselleşen dünyada üretilen ürün miktarının ve çeşitliliğin çok olmasından ötürü yeni ürünlere hızla ve kolaylıkla ulaşma isteği duymaya başlamışlardır. Bu yüzden de işletmeler için önemli olan yeni ürünün mümkün olduğu kadar hızlı bir şekilde piyasaya sürülmesi olmuştur. Bu durum ise, Endüstri 4,0'ın önemli hale gelmesinde en temel sebeplerden birisidir(Pamuk,2017:5).Bir diğer sebep ise, Üretimin daha esnek ve daha ucuz bir şekilde yapılmasını sağlamaktır. Ayrıca Doğu-Batı ülkeleri arasındaki hammadde tedariki problemini ortadan kaldırmak bu nedenler arasında sayılabilmektedir. Endüstri 4.0'ın gerçekleşmesi için çeşitli elemanlara ihtiyaç vardır.

Endüstri 4.0’ın elemanları; Nesnelerin İnterneti, Siber-Fiziksel Sistemler, Yatay ve Dikey Entegrasyon, Büyük veri ve veri analitiği, Akıllı Fabrikalar, Bulut Bilişim, Arttırılmış Gerçeklik, Siber Güvenliktir. 
Nesnelerin İnterneti; Nesnelerin birbiriyle haberleşmesini imkânlı hale getiren yapılara Nesnelerin İnterneti (loT) ismi verilmektedir. Nesnelerin interneti, her şeyin interneti olarak da isimlendirilmemektedir. Bu yeni teknolojik kavram sayesinde, bir ağ üzerinde birbirleri ile iletişim kabiliyetine sahip makineler ve cihazlar ifade edilir (Lee ve Lee; 2015:431). Nesnelerin İnterneti kavram olarak ilk kez Ashton tarafından 1999 yılında Procter \&Gamble şirketine yapılan sunum sırasında ifade edilmiștir(Şekkeli ve Bakan,2018:21). Nesnelerin interneti denildiğinde akla ilk gelen, internete bağlı bilgisayar, telefon, tablet gibi nesnelere ek olarak daha birçok farkı nesneler de internete bağlanarak birbirleri ile haberleşmektedirler. Örnek olarak, evdeki buzdolabının, bitmek üzere olan gıda maddelerini süpermarkete listeleyerek istekte bulunması; aracınızın benzinin ne kadar kaldığını, trafikteki tıkanıklı̆ı ya da boş park yerlerini algılayarak sürücüye mesaj yoluyla iletilmesi gibi örnekler verilebilir. Nesnelerin interneti kullanım alanı olarak birçok alanda kullanılmaktadır. Bu alanlar, doğal çevre uygulamaları, alt ve üst yapı uygulamaları, endüstriyel uygulamalar, engelliler için uygulamalar, enerji yönetimi, sağlık sistemleri ve nakliye sistemleri uygulamaları olarak sayılabilir(Şekkeli ve Bakan,2018:22).

Siber Fiziksel Sistemler; Fiziksel dünya ile siber dünya arasındaki iletişim ve bütünleşmeyi içeren yapıların tümü Siber- fiziksel sistemler olarak isimlendirilir.

Endüstri 4.0, internetin ve olarak ve fiziksel ve sanal dünyayı bir araya getiren sistemler olarak kabul edilebilen eşi görülmemiş bir bağlantı ile kodlanmasıdır. Kısaca, siber-fiziksel sistemler fiziksel süreçlerle hesaplamanın bütünleştirilmesidir.

Yatay Ve Dikey Entegrasyon: Yatay entegrasyon, üretim ve planlama sürecindeki her bir adımın kendi arasında, ayrıca farklı işletmelerin üretim ve planlama süreçlerindeki adımlar arasında kesintisiz bir akış demektir.Hammadde tedarikinden; üretim, pazarlama ve nakliyeye kadar bütün süreçleri kapsamaktadır(www.endüstri4.0platformu.com,20.05.2018). Dikey entegrasyon, tüm süreçlerde kullanılan teknolojik alt yapıda kesintisiz bir haberleşme ve akışın sağlanmasıdır(Ersoy,2016:10). Büyük Veri Ve Veri Analitiği; Günümüz iş dünyasında veriler makineler ve cihazlar yardımıyla üretilip bulut alt yapılı sistemler içerisinde saklanmaktadır. (Roblek vd., 2016). ihtiyaç duyulduğu anda işletme yöneticileri veya tüketiciler bu verilere kolayca ulaşabilir. Ağlardaki verilerin büyüklügünün ilerleyen yıllarda çok daha fazla olacağı düşünülmektedir. Bundan dolayı da, büyük veri Endüstri 4.0 için kritik bir faktördür(Yin ve Kaynak, 2015). Akıllı Fabrikalar; Son zamanların yeni kavramları olan büyük veri, robot teknolojileri, nesnelerin interneti gibi sistemler ile akıllı fabrikalar ortaya çıkmıştır. Akıllı fabrikalar hayali geçip artık zorunluluk halini alacaktır, bundan ötürü ise tüketici taleplerin karşılamak için işletmeler, fabrikalarında dönüşüm yapmaya mecbur kalacaklardır. Endüstri 4.0'ın üretim süreci, müşterinin talepleri ve tedarikçiden toplanan verilerin analiz edilmesi sonucu akıllı fabrikalar, robot teknolojisinin yardımı ile kolay bir şekilde ürünün üretilmesi sağlanabilecektir. RFID (Radyo Frekansı ile Tanımlama) etiket sensörleri yardımı ile akıllı robotlar üretim bandındaki ürünü tanıyarak işlem gerekliliklerini yerine getirebileceklerdir. Bu sayede farklı ürünler aynı üretim bandında hiç hatasız çıkışı sağlanabilecektir(Bulut,2017:56). Bulut Bilişim; Bulut bilişim Endüstri 4.0 başarısındaki diğer bir önemli faktördür. Bulut bilişim müşteriler tarafından oluşturulan taleplere cevap vermek için verimliliği artırarak, ürün maliyetlerini düşürüp, optimum kaynak sağlanmasına izin veren aynı zamanda siber-fiziksel üretim hatları oluşturarak paylaşılan çeşitlendirilmiş ve dağııılan üretim kaynaklarının bir paylaşım mantığı ile bir ağa bağlı üretim modelidir(Yıldız,2018:550). Artıııımış Gerçeklik; Zenginleştirilmiş gerçeklik, Grafik ortamında ses, video, grafik ya da GPS verileri ile bilgisayarlar yardımı ile üretilip insanların duyularına hitap edecek şekilde dijital platformlarda canlandırımasıdır. Bu canlandırma ile fiziksel ve gerçek alanda birleşme sağlanmakta ve kullanıcıya yeni bir algılama alanı oluşturulmaktadır. Yeni algı alanı canlı olarak doğrudan doğruya ya da dolaylı görseller yardımıyla yansıtabilmektedir. Bu sistemde insan duyularına hitap edecek ve duyuları etkileyecek girdiler dijital ortamda zenginleştirilerek simüle edilebilir ve sonrasında arttırılmış bu gerçeklik kullanııının algısına sunulmaktadır(www.endüstri4.0.com,20.05.2018). Siber Güvenlik; Siber güvenlik veri güvenliğinin kontrol altında tutulmasını sağlamak olarak tanımlanır. Aksi durumda cihazların internette aktif olarak bulunmalarından dolayı veri kaybına ve bilgi güvenliğinin sağlanamamasına sebep olabilmektedir. Siber güvenlik sistemleri firmaların güvenliğini sağlayarak fiziksel iletişimin sağıklı ortamda sürdürülebilmesini sağlamaktadır (Bulut,2017:57).

\section{SONUC}

Günümüz ortamında geleneksel üretim teknikleri ile rekabet edebilmek oldukça zor hale gelmeye başlamıştır. Bu sebeple hem yöneticiler hem de akademisyenler, rekabetin sürdürülebilir hale gelmesini sağlamak için yeni yollar aramaya başlamışlardır. Öte yandan, teknoloji her alanda sürekli ve durmadan gelişmektedir. Artık teknoloji sayesinde birçok soruna çözüm bulunur hale gelmiştir. Bu yenilik arayışlarının teknolojik gelişmelerle entegrasyonu, bir devrim olarak nitelendirilen Endüstri 4.0 kavramının ortaya çıkmasını sağlamıştır(Şekkeli ve Bakan,2018:31). Endüstri 4.0 üretimde köklü değişimlere yol açacak teknolojileri geliştirmeyi ve uygulamayı öngören bir anlayıştır(Dengiz,2017:43).Bu kavram ise geleceğin üretim ortamı konusunda bizlere öngörücülük yapmaktadır. Işletmeler için yeni ürün geliştirmek hayati kararlardan birisidir bunun farkında olan işletme yöneticileri geleneksel üretimden vazgeçip akıllı üretim anlayışları aramaya başlamak zorundadırlar. Bu yeni anlayış olan Endüstri 4.0 yardımı ile işletmeler yeni ürün üretirlerken tüketici istek ve ihtiyaçlarına daha hızlı ve ucuz bir yolla cevap verebilecek ve aynı zamanda yeni ürünlerin piyasaya sürülme sürelerini kısaltarak üretimde verimliliği artıracaktır. Bunlara ek olarak iş gücü için yeni bir iş kapısı olacağı öngörülmektedir.

\section{KAYNAKLAR}

Bulut, E., Akçacı, T. (2017). Endüstri 4.0 ve inovasyon göstergeleri kapsamında Türkiye analizi. ASSAM Uluslararası Hakemli Dergi, 4(7), 55-77.

Cengiz, E., Ayyıldız, H., Kırkbir, F. (2005). Yeni ürün geliştirme sürecinin başarısında etkili olan faktörler. Erciyes Üniversitesi İktisadi ve İdari Bilimler Fakültesi Dergisi, Sayı: 24, ss. 133-147.

Çeliktaş, M. S., Sonlu, G., Özgel, S., Atalay., Y. (2015). Endüstriyel devrimin son sürümünde mühendisliğin yol haritası. Endüstri ve Mühendislik Dergisi, 56(662), 24-34.

Dengiz, O. Endüstri 4.0: Üretimde kavram ve algı devrimi. Makina Tasarım ve İmalat Dergisi, 15(1), 38-45. 
Ecer, H., Canıtez, M. (2004). Pazarlamanın ilkeleri teori ve yaklaşımlar. Gazi Kitapevi, Ankara, 340s.

Jänicke, M., Jacob, K. (2009). A third industrial revolution? Solutions to the crisis of resource-intensive growth.

Lee, I., Lee, K. (2015). The Internet of Things (IoT): applications, investments, and challenges for enterprises. Business Horizons, 58(4): 431440.

Macdougall, W. (2014). Industrie 4.0 smart manufacturing for the future. Germany Trade and Invest, July 2014.

Ovacı, C. (2017). Endüstri 4.0 çağında açık inovasyon. Maliye Finans Yazilari.

Sanders, N. R., Manrodt, K. B. (1994). Forecasting practices in US corporations: survey results. Interfaces, 24 (2), pp.92-100.

Soysal, M., Pamuk, N. S. Yeni sanayi devrimi endüstri 4.0 üzerine bir inceleme. Verimlilik Dergisi, (1), 41-66.

Srinivasan, R., Brush, T. H. (2006). Supplier performance in vertical alliances: the effects of self-enforcing agreements and enforceable contracts. Organization Science, Vol. 17 No. 4, pp. 436-452.

Şekkeli, Z. H., Bakan, İ. (2018). Endüstri 4.0'ın etkisiyle lojistik 4.0. Journal of Life Economics, 5(2), 17-36.

Yıldız, A. (2018). Endüstri 4.0 ve akıllı fabrikalar. Sakarya University Journal of Science, 22(2), 548-558.

Yın, S., Kaynak, O. (2015). Big data for modern industry: challenges and trends. Proceedings of the IEEE, Cilt: 103, Sayı: 2, s. $143-146$. 